\title{
Pharmacologic Management of Persistent Pain in Cancer Survivors
}

\author{
Paul Glare ${ }^{1,2} \mathbb{D} \cdot$ Karin Aubrey ${ }^{1,2} \cdot$ Amitabh Gulati $^{3} \cdot$ Yi Ching Lee $^{2,4,5} \cdot$ Natalie Moryl $^{3} \cdot$ Sarah Overton $^{6}$
}

Accepted: 10 January 2022 / Published online: 17 February 2022

(c) The Author(s) 2022

\begin{abstract}
Improvements in screening, diagnosis and treatment of cancer has seen cancer mortality substantially diminish in the past three decades. It is estimated there are almost 20 million cancer survivors in the USA alone, but some $40 \%$ live with chronic pain after completing treatment. While a broad definition of survivorship that includes all people living with, through and beyond a cancer diagnosis - including those with active cancer-is often used, this narrative review primarily focuses on the management of pain in people who are disease-free after completing primary cancer treatment as adults. Chronic pain in this population needs a different approach to that used for people with a limited prognosis. After describing the common chronic pain syndromes caused by cancer treatment, and the pathophysiologic mechanisms involved, the pharmacologic management of entities such as post-surgical pain, chemotherapy-induced neuropathy, aromatase inhibitor musculoskeletal syndrome and checkpoint inhibitor-related pain are described. The challenges associated with opioid prescribing in this population are given special attention. Expert guidelines on pain management in cancer survivors now recommend a combination of pharmacologic and non-pharmacologic modalities, and these are also briefly covered.
\end{abstract}

\section{Key Points}

Chronic pain following cancer treatment is common. In survivors with an excellent prognosis, a biopsychosocial approach to pain management is recommended.

The use of long-term opioid therapy in this population raises the same concerns as it does in chronic non-malignant pain.

Adjuvant analgesics have an important role, as neuropathic pain is common in cancer survivors.

Paul Glare

paul.glare@sydney.edu.au

1 Pain Management Research Institute, Kolling Institute, University of Sydney and Northern Sydney Local Health District, Sydney, NSW, Australia

2 Faculty of Medicine and Health, University of Sydney, Sydney, NSW, Australia

3 Memorial Sloan Kettering Cancer Center, New York, NY 10065, USA

4 Chris O'Brien Lifehouse, Sydney, NSW, Australia

5 Royal Prince Alfred Hospital, Sydney, NSW, Australia

6 Pain Management Research Centre, Royal North Shore Hospital, Sydney, NSW, Australia

\section{Introduction}

Advances in cancer management (earlier detection and better treatment) in the past 30 years have seen cancer change from a terminal illness to a chronic one. In the United States, the National Cancer Institute (NCI) estimates there was a 31\% decrease in cancer mortality between 1990 and 2018, with approximately two-thirds people with cancer now living 5 years beyond diagnosis [1]. According to Cancer Research UK, half the people diagnosed with cancer in Britain will live at least 10 years (https://www.cancerresearchuk.org/ health-professional/cancer-statistics/survival, accessed 22 November 2021). As a result of the decrease in cancer mortality, the number of cancer survivors has increased, in the case of the United States from approximately 3 million in 1971 to more than 15 million in 2016 [2]. These numbers are predicted to exceed 20 million by 2026 and 26 million by 2040 .

Unfortunately, improved cancer survival comes at a cost as patients may experience adverse physical and psychosocial effects from the diagnosis and its treatment. These adverse effects can be severe, debilitating and persistent, sometimes permanent. Pain is one such adverse effect and all modalities of cancer treatment-surgery, chemotherapy, radiation therapy (RT), transplants and immunotherapy — can be painful. Acute pain becomes chronic in 
approximately $10-20 \%$ cases [3], causing distress and disability that reduces the quality of life long term.

Twenty years ago, when the outlook of a cancer diagnosis was less optimistic, cancer treatment-related pain was classified as a subset of cancer pain and was mainly treated with opioids [4]. Nowadays, the use of opioids in cancer survivors with chronic pain is raising the same concerns as it does in patients with chronic non-malignant pain. This is especially so when the patient has completed definitive treatment for early-stage disease and the prognosis is good [5]. Furthermore, there is increasing recognition that chronic non-malignant pain is a common comorbidity in cancer survivors [6] and opioids are no longer recommended for this condition [7]. Consequently, the American Society of Clinical Oncology (ASCO) guideline on the management of pain in cancer survivors ranks opioids as third-line treatment [8].

Numerous reviews of the broad topic of pain in cancer survivors have been published. Some are comprehensive [9], while others focus on specific issues. Subsequent to the ASCO guideline being published in 2016, there have been a small number of broad reviews of survivor pain treatment $[10,11]$. The aim of this narrative review is to provide an update of the etiology and management of chronic pain in cancer survivors, with the emphasis of management being on pharmacological treatments. However, because pharmacological approaches are not effective in all cases, some nonpharmacological approaches are also presented. This review is restricted to pain in survivors of adult cancers; pain in survivors of paediatric cancer has been reviewed recently by others [12].

\section{Definition of Pain in Cancer Survivors}

Before reviewing the pharmacological management of pain in cancer survivors, consideration needs to be given to who is included under the 'cancer survivor' label and what kind of pain is being referred to. According to the NCI's Office of Cancer Survivorship, an individual is considered a cancer survivor "from the time of diagnosis throughout the balance of his or her life" https://cancercontrol.cancer.gov/ocs/stati stics\#definitions. Furthermore, family, friends and voluntary caregivers who are affected by the diagnosis in any way are included as 'survivors'. Accordingly, survivors are not only those free of disease but also those living with cancer. A broad survivorship definition has benefits, for example including people with treatable, slow-growing tumours who may be on treatment intermittently, as well as those who have incurable disease that is controlled with systemic therapy, some of whom live with incurable cancer for 10-20 years while fully functional [2]. However, this broad definition implies that cancer-related pain, for which unlimited amounts of opioids are generally considered appropriate, would be within the scope of a review on cancer survivor pain. Furthermore, patients living with cancer have different psychosocial issues to disease-free survivors as they cope with living with an eventually terminal diagnosis. This situation may impact on pain management (e.g. uncertainty about the durability of the response to cancer treatment; how to handle comorbid conditions and disease prevention, screening and treatment in the setting of limited life expectancy; and managing discussions regarding new drugs and earlystage clinical trials) [2].

The Survivorship Taskforce of the European Organization for Research and Treatment of Cancer takes a narrower approach to defining survivors, limiting it to those who have completed primary treatment (with the exception of maintenance therapy) and have no active disease [13]. Pain arising from the diagnosis and treatment of premalignant conditions (e.g. ductal carcinoma in situ, cervical intraepithelial neoplasia, non-invasive skin cancers, myelodysplasia and benign central nervous system tumours) would also be included using this definition.

However, even accepting a narrow definition of survivorship, further clarification of the type of pain is needed. Most cancer treatment-related pain is short-lived and not persistent, procedural pain being especially problematic in paediatric oncology [14]. Cancer survivors may also have concomitant chronic pain that is not directly attributable to cancer or its treatment; given that cancer is usually a disease of middle/older age, comorbid non-malignant pain syndromes are common in the oncology population [6]. Both treatment-related pain and comorbid non-malignant pain may occur concurrently, the latter often aggravated by the physical and emotional effects of the cancer diagnosis and treatment.

In summary, this narrative review assumes a narrow definition of survivorship and focuses on chronic pain directly attributable to cancer treatment. The scope of the article is as follows:

- Adults who have had cancer or pre-malignant tumour diagnosed and treated after the age of 18 years.

- They have completed primary/first-line treatment (typically for early-stage disease and given with curative intent).

- They do not currently have evidence of active disease.

- Their pain is attributed to the administration of anti-cancer treatment.

- The pain has persisted beyond the usual time expected for the tissue damaged by the treatment to recover.

Many adult cancer survivors have chronic pain after treatment. With the prevalence estimated to be up to $40 \%$ [15], this equates to 8 million individuals in the USA alone. This number is expected to continue to grow as the population 
ages, more cancer is diagnosed and cancer treatments and supportive care continue to improve.

\section{Common Cancer Treatment-Related Pain Syndromes}

All modalities of cancer treatment may cause acute pain that persists beyond the time for healing in approximately $20 \%$ of patients [16]. Some patients develop persistent pain on maintenance treatments that are continued long-term after initial treatment was completed, such as breast cancer survivors with aromatase inhibitor-related musculoskeletal syndrome (AIMSS) [17]. In a few cases, chronic pain can occur as a late effect, remote in time from the administration of treatment such as radiation plexopathy [18]. Some of the most common chronic pain syndromes related to cancer treatment, their prevalence and established risk factors are shown in Table 1. Clearly, disease recurrence, paraneoplastic syndromes and unrelated rheumatic or neurologic diseases should be considered as potential differential diagnoses of cancer treatment-related pain, and the comprehensive patient assessment should be focused on ruling out evidence of disease based on history, clinical features, laboratory tests, imaging and/or biopsy.

\subsection{Neuropathic Pain After Cancer Treatment}

Although many different types of normal tissue may be damaged by cancer treatment, nerve damage is common. It can follow the conventional cancer treatment modalities of surgery, chemotherapy and/or RT.

\subsubsection{Persistent Pain Post-cancer Surgery}

Chronic pain has been reported after almost all types of surgery, with a higher prevalence $(>20 \%)$ reported in sites that are common surgical fields in oncology, such as breast, thorax and spine [19]. While the high prevalence of persistent pain post-cancer surgery is often attributed to iatrogenic nerve injury, there are other contributors including central sensitization and comorbid pre-existing pain in the operated area [19].

Persistent pain post-breast cancer surgery (PPPBCS, also known as post-mastectomy syndrome) is perhaps the most well documented cancer treatment pain syndrome, with many studies and reviews of the topic being published in the past two decades. PPPBCS has been estimated to affect as many as two women in three, and is moderate to severe in 15-20\% of cases 1-year post-surgery [20]. The exact mechanism of PPPBCS is unknown, but is usually attributed to damage of nerves such as in the chest wall or axilla (e.g. intercostobrachial nerve) during surgery.
Consequently, it is often reported with typical neuropathic descriptors, such as burning, shooting, as well as mechanical allodynia and deep blunt pain. PPPBCS can begin shortly after surgery but may not come on for several months and can go on for years. In fact, pain is more common after minimally invasive surgery (lumpectomy) than mastectomy. It may be located in the axilla, the shoulder, arm or chest wall. Risk factors include young age, axillary dissection and sectioning of the intercostobrachial nerve. Introduction of sentinel node biopsy has reduced but not eliminated the prevalence of PPPBCS [21].

Validated prediction models have been developed to screen for patients at high risk of developing PPPBCS. In one model, preoperative pain in the operative area $(p<0.001)$, high body mass index $(p=0.039)$, axillary lymph node dissection $(p=0.008)$ and more severe acute postoperative pain intensity at the seventh postoperative day $(p=0.003)$ were included in the final prediction model [20]. An online risk calculator has been developed to operationalize the model. Machine learning has also been utilized in predicting PPPBCS, with 21 single or aggregated parameters being identified including demographic features, pain-related variables and psychological characteristics. This method had a cross-validated accuracy of $86 \%$ and a negative predictive value of approximately 95\% [22].

Post-thoracotomy pain syndrome (PTPS) occurs with a prevalence ranging from 25 to $57 \%$, although severe in $<10 \%$ [23]. Post-thoracotomy pain is predominantly neuropathic in nature, and as with PPPBCS, the etiology is usually attributed to surgical nerve damage, being less common after minimally invasive surgery (e.g. videoscopic-assisted surgery) than open thoracotomy. Unlike PPPBCS, preoperative risk stratification of susceptible individuals for PTPS is not well established [23]. Adjuvant radiation and chemotherapy appear to predispose patients to developing chronic PTPS. Poor postoperative pain management (first 24 hours after surgery) was the sole factor that predicted the development and severity of long-term pain. Psychologic factors are also important, including preoperative anxiety, somatization and pain catastrophizing [23].

Other major cancer surgeries commonly associated with chronic pain afterwards include neck dissection [24], colorectal surgery [25], and post-nephrectomy pain [26].

\subsubsection{Chemotherapy-Induced Peripheral Neuropathy (CIPN)}

Neuropathy is one of the most common complications of chemotherapy. Several classes of chemotherapeutic agents are neurotoxic, including the platinum-based compounds, taxanes, vinca alkaloids, thalidomide derivatives and proteasome inhibitors. Newer classes of chemotherapeutic agents including molecular-targeted agents like ado-trastuzumab 
Table 1 Common chronic pain syndromes related to cancer treatment [23]

\begin{tabular}{|c|c|c|c|}
\hline Pain syndrome & Treatment modality & Incidence/prevalence & Risk factors \\
\hline \multicolumn{4}{|l|}{ Neuropathic pain } \\
\hline \multirow[t]{5}{*}{ Persistent pain post-cancer surgery } & Breast cancer surgery [20-22] & $\begin{array}{l}20-68 \% \\
15-20 \% \text { moderate-severe at } 1 \text { year }\end{array}$ & $\begin{array}{l}\text { Young age } \\
\text { High BMI } \\
\text { ALND } \\
\text { Acute post-operative pain } \\
\text { Psychological characteristics }\end{array}$ \\
\hline & Thoracotomy & $\begin{array}{l}25-57 \% \\
\text { Severe: }<10 \%\end{array}$ & $\begin{array}{l}\text { Adjuvant chemotherapy/RT } \\
\text { Acute post-operative pain } \\
\text { Psychological characteristics }\end{array}$ \\
\hline & Neck dissection [24] & $0-100 \%$ & Not yet identified \\
\hline & Colorectal surgery [25] & $22 \%$ at 6 months & $\begin{array}{l}\text { Young age } \\
\text { Peoperative abdominal pain } \\
\text { Preoperative anxiety } \\
\text { Longer duration of surgery } \\
\text { High pain intensity on movement } \\
\text { within } 24 \text { h after surgery }\end{array}$ \\
\hline & Nephrectomy [26] & $4 \%$ at 6 months & Not yet identified \\
\hline $\begin{array}{l}\text { Chemotherapy-induced peripheral } \\
\text { neuropathy }[27-30]\end{array}$ & & $\begin{array}{l}60 \% \text { at completion } \\
30 \% \text { at } 6 \text { months }\end{array}$ & $\begin{array}{l}\text { Older age } \\
\text { Type of chemotherapy (platinum > } \\
\text { taxane) } \\
\text { Number of cycles } \\
\text { PN, diabetes, statins } \\
\text { Smoking, alcohol }\end{array}$ \\
\hline Chronic pain post-RT [18] & $\begin{array}{l}\text { Gynecologic } \\
\text { Head and neck } \\
\text { Lung apex } \\
\text { Breast }\end{array}$ & $\begin{array}{l}39 \% \\
15 \% \\
12 \% \\
2 \%\end{array}$ & $\begin{array}{l}\text { Type of cancer } \\
\text { Total dose } \\
\text { Large dose per fraction } \\
\text { Surgery, chemotherapy }\end{array}$ \\
\hline \multicolumn{4}{|l|}{ Nociceptive pain } \\
\hline $\begin{array}{l}\text { Musculoskeletal pain post-surgery } \\
\text { or RT }\end{array}$ & & Variable & Not identified \\
\hline $\begin{array}{l}\text { Aromatase inhibitor-associated mus- } \\
\text { culoskeletal syndrome [17] }\end{array}$ & & $\begin{array}{l}\text { Up to } 50 \% \\
28 \% \text { discontinue treatment }\end{array}$ & $\begin{array}{l}\text { Younger age } \\
\mathrm{BMI}>30 \\
\text { Prior taxane chemotherapy }\end{array}$ \\
\hline $\begin{array}{l}\text { Rheumatic and musculoskeletal pain } \\
\text { associated with checkpoint inhibi- } \\
\text { tors [43] }\end{array}$ & & Up to $22 \%$ & Not yet identified \\
\hline $\begin{array}{l}\text { Joint and fascia manifestations of } \\
\text { chronic graft vs host disease [45] }\end{array}$ & & $29 \%$ & Not yet identified \\
\hline
\end{tabular}

$A L N D$ axillary lymph node dissection, $B M I$ body mass index, $P N$ peripheral neuropathy, $R T$ radiation therapy

emtansine, brentuximab vedotin and the checkpoint inhibitors have also been associated with the development of neuropathic pain [27]. Although these agents are neurotoxic due to various pathological mechanisms (see Sect. 3.1.3), clinically they tend to all present as a symmetrical sensorypredominant peripheral neuropathy that may be associated with significant pain. Some $60 \%$ of individuals exposed to neurotoxic chemotherapy agents develop CIPN [28]. In one recent study, the type of chemotherapy (most common after platinum-based chemotherapy) and number of cycles received was associated with a higher incidence of CIPN [29]. A number of non-chemotherapy-related risk factors have also been identified. Older age, history of pre-existing neuropathy, symptom burden and alcohol intake were independent risk factors on multivariate analysis. Statins and diabetes mellitus were implicated on univariate analysis [29]. Smoking, abnormal creatinine clearance and specific sensory changes during chemotherapy have also been implicated. Although the prevalence of CIPN decreases with time, $30 \%$ of patients report it 6 months post-treatment [28]. Those surviving $>5$ years often continue to have substantial impairments [30].

\subsubsection{Chronic Pain Post-radiation Therapy}

While RT plays an important role in palliation of painful cancer deposits, it may also be the source of treatmentrelated pain, albeit rarely. Its occurrence is better recognized 
with improved long-term cancer survival. Onset can be within a few months of the end of RT or up to several years later. Chronic enteritis, cystitis, proctitis, osteoradionecrosis, pelvic fractures and chest wall pain are all described, along with various neuropathic pains (plexopathies, peripheral nerve entrapments and myelopathy) [18]. Risk factors include large overall treatment dose, large dose per RT fraction and combined treatment with surgery or chemotherapy.

Although overall the incidence of post-RT pain is falling, nevertheless, it occurs in $2 \%$ of breast cancer survivors and up to $15 \%$ of head and neck cancer survivors [31].

The most widely recognized form of post-RT pain is chronic neuropathic pain after breast cancer treatment [32]. Chronic painful radiation-induced neuropathies usually occur several years after RT and are often progressive and irreversible. Brachial plexopathy is more common after treatment of apical lung cancer (incidence $12 \%$ at 3 years) [33] than breast cancer [32]. Symptoms of post-RT brachial plexopathy begin any time from 6 months to 20 years (median time 1.5 years) after treatment and progressive weakness is common. In the past, pain has been documented as severe enough to need opioids in $50 \%$ of cases.

Chronic pain is also described after RT for head and neck cancer [34], gynaecological cancer [35] and prostate cancer [36]. Despite advances in RT techniques, patients with head and neck cancer may experience oral complications up to 6 months later, with resulting negative impacts on oral function and quality of life. In a prospective, multi-centre, longitudinal cohort study of 372 patients with head and neck cancer who received high-dose RT with curative intent, mean overall pain score was unchanged from baseline at 6 months in 216 evaluable patients, although it was mild on average (score only $9.2 \pm 17.7$ on a $0-100$ score) [34]. Patients also complained of other persisting symptoms impairing oral health-related quality of life at 6 months including dry mouth, sticky saliva, difficulty swallowing solid foods and dysgeusia. Gynaecological cancer survivors can develop lumbosacral plexopathy after pelvic RT and axial neuropathy of the spinal cord after cervical RT. Women previously treated with pelvic radiation report a higher occurrence of symptoms from the urinary and gastrointestinal tract as well as lymphedema, sexual dysfunction and pelvic pain. In a Scandinavian study that compared women who had been treated for various gynaecological malignancies ( $>80 \%$ of whom had endometrial or cervical cancer) and were on average 6 years out from completing RT with age-matched controls who had not been treated for cancer, the most prevalent problems were pelvic bone pain (39\%), dyspareunia (17\%), abdominal pain (12\%), dysuria (10\%) and genital pain $(5 \%)$ [35]. While erectile dysfunction is the most well-known side effect of RT for prostate cancer, other changes in sexual function may occur, including orgasm-associated pain (15\%) and painful erections (6\%) [36]. Penile paraesthesias or cold sensations occurred in $2 \%$. Increasing time since final treatment increased the risk of penile sensory disturbances.

\subsection{Nociceptive Pain}

Some of the more common examples include

1. Musculoskeletal pain following surgery [37] and/or RT. While the main pain syndromes following surgery and or RT are neuropathic, somatic tissues such as skin, muscle, fascia and bone can also be damaged by these modalities. Scarring and fibrosis of soft tissues results in misalignment and pain. For example, rotator cuff syndrome is common following breast cancer surgery due to misalignment of the subacromial space [38].

2. AIMSS. Joint and muscular symptoms occur in up to half of breast cancer survivors receiving long-term adjuvant treatment with third-generation aromatase inhibitors (AI) such as anastrozole, letrozole and exemestane. These symptoms are bad enough to cause $>25 \%$ of patients to discontinue treatment, adversely impacting survival [17]. They typically report pain or soreness in the hands, knees, hips, lower back, shoulders and feet beginning during the first few months of treatment. Difficulty sleeping and early-morning stiffness are commonly reported. Extra-articular manifestations include myalgia, fibromyalgia, neuropathy and carpal tunnel syndrome. While AI are generally used in post-menopausal women, younger age, higher BMI and taxane chemotherapy have been identified as risk factors for AIMSS [39]. In patients with AIMSS, switching AI therapy to a different agent is often effective [39-41].

3. Immunotherapy-related pain. Checkpoint inhibitors (monoclonal antibodies targeting immunological checkpoints) such as ipilimumab, nivolumab, and pembrolizumab have become available during the past 10 years and are being used increasingly in oncology. These agents work by activating $\mathrm{T}$ cells, so they produce a variety of inflammatory, autoimmune-like effects. They are unlike other cancer toxicities, affecting almost any organ system, but most often the skin, gastrointestinal tract, endocrine system glands and lungs [42]. Painful rheumatological syndromes are also common, occurring in $1.5-22 \%$ of patients [43]. These can include arthralgia, arthritis, myalgia, myositis, dry mouth, musculoskeletal pain and back pain.

4. Chronic graft versus host disease (cGVHD) following transplantation. cGVHD can occur after bone marrow or stem cell transplantation for adult haematological malignancies. It is a complex systemic disease with a wide spectrum of clinical features. cGVHD may be active for years, or even decades, requiring potentially years of immunosuppressive therapies and placing patients at 
risk for a number of late complications. Painful manifestations may include scleroderma, myositis, fasciitis, joint stiffness and sicca syndrome of eyes and mouth [44], and joint and fascia complications occurred in $29 \%$ in one series [45]. The gastrointestinal tract can also be involved, including the liver and pancreas.

\section{Pathophysiology of Cancer Treatment-Related Pain Syndromes}

Painful stimuli are sensed by nociceptors in the peripheral nervous system (PNS) and nociceptive information is then passed to the central nervous system (CNS) at the level of the spinal cord and then sent to higher brain regions via several ascending pathways [46, 47]. Integration of these sensory signals with cognitive and emotional states in the brain leads to activation of descending pain pathways that can directly modulate incoming nociceptive information. Dysfunction in any part of this pathway, including the nonsensory components, can contribute to the development of chronic pain [3, 48-50].

In animal models, chronic pain is induced by sustained peripheral inflammation or nerve injury [51]. These prolonged injuries cause diverse neuronal adaptations that increase the responsiveness of both PNS and CNS nociceptive circuits, referred to as peripheral and central sensitization, respectively [52]. The two most frequent types of prolonged injury caused by cancer treatments occur due to surgery $[19,53]$ or treatment with chemotherapy agents [37, 54-56]. The pathophysiological changes that can result from surgery and chemotherapy may be targets for novel treatment approaches and are summarized in Table 2.

\subsection{Post-surgical Pain Mechanisms}

Surgery can lead to prolonged inflammation (e.g. due to wound infection or dysregulated inflammatory response) and/or directly damage peripheral nerves. In this context, it is unsurprising that cancer treatments with surgery as a modality are often associated with the development of chronic pain. The mechanisms include glutamate release, changes in n-methyl d-aspartate receptors, and calcium influx leading to neuronal death [19]. mRNA-mediated protein synthesis leading to centralization is another postsurgical mechanism [19].

\subsection{Post-chemotherapy Pain Mechanisms}

Chemotherapy is not perfectly targeted to cancer cells, so is cytotoxic in normal tissues, including those of the nervous system. Peripheral nerves originating from neurons in the
Table 2 Pathophysiological changes caused by cancer treatment, which may be targets for novel treatment options in chronic treatment-related pain

$\begin{array}{ll}\text { Cancer surgery } & \begin{array}{r}\text { Glutamate release, NMDA receptor changes, and } \\ \text { calcium ion influx in dorsal horn of spinal cord } \\ \text { mRNA-mediated protein synthesis in spinal cord } \\ \text { Axonal degeneration } \\ \text { Mitochondrial damage }\end{array} \\ & \text { Increased reactive oxygen species } \\ & \text { Altered calcium homeostasis } \\ & \text { Altered ion channel expression } \\ & \text { Increased inflammatory cytokines } \\ & \text { Increased TLR4 receptor expression on glial cells }\end{array}$

dorsal root ganglion (DRG) are particularly susceptible to damage as the blood-brain barrier does not protect them. In addition, DRGs are intensely vascularized and maintained by a complicated nerve repair and regeneration process, which is altered by chemotherapy agents [37, 56-58]. Understanding the mechanisms that generate peripheral neuropathy is essential to help to identify and develop effective treatment options and guide the selection of appropriate analgesic therapies.

Paclitaxel and oxaliplatin are commonly used chemotherapeutic agents that are neurotoxic. They are cytotoxic to cancer cells via different mechanisms. Paclitaxel and other taxanes (e.g. docetaxel, cabazitaxel) are microtubule-stabilizing agents that impair cell division $[59,60]$, while platinum-based chemotherapies such as oxaliplatin are alkylating agents that binds to cellular DNA to inhibit cell RNA transcription and replication [61, 62]. Paclitaxel and oxaliplatin produce a plethora of changes in the PNS that lead to CIPN. Both cause axonal degeneration [63], mitochondrial damage, increased reactive oxygen species, altered calcium homeostasis, changes in ion channel expression [54-57] and modulation of the inflammatory and immune systems [37, 64]. However, it is still unclear which molecular changes occur first, which mechanisms are shared by both drug types and how each change contributes to nerve damage.

Although both paclitaxel and oxaliplatin neurotoxicity manifests as 'glove and stocking' neuropathies, the acute effects of these drugs trigger neuropathic symptoms that are distinct with respect to sensation, timing, severity and recovery [61]. Paclitaxel usually leads to painful sensations in both the hands and feet, often described as an aching sensation, which does not become worse after repeat treatments. By contrast, oxaliplatin affects the hands more strongly than the feet, gets progressively worse with each subsequent treatment, and produces a cold-induced neuropathy (attributed to a metabolite of oxaliplatin $[65,66])$. These data suggest that the mechanisms by which paclitaxel and oxaliplatin initiate nerve damage are distinct. Understanding these mechanisms 
may help identify medications that can protect peripheral neurons from the cytotoxic effects before they occur.

One example of a neuroprotective strategy that is currently undergoing clinical trials is based on the observation that both taxanes and platins accumulate in DRGs [67]. The level of the cytotoxic drug held in DRGs can remain elevated for a prolonged period, and higher intracellular levels correlate with more severe CIPN $[68,69]$. Building on previous work $[55,70,71]$, some recent pre-clinical studies have systematically applied knock-out strategies to assess which transporters are required for concentrating paclitaxel and oxaliplatin in sensory neurons $[72,73]$. This work showed that the organic anion transporting polypeptide (OATP1B2) is necessary for paclitaxel accumulation in DRGs and triggers acute and tonic pain behaviours [72]. In contrast, knockout of OATP1B2 did not interfere with oxaliplatin-induced pain behaviours [73]. Instead, these were dependent on the organic cation transporter 2 (OCT2). Thus, compounds that prevent OATP1B2- [72] and OCT2-dependent [73, 74] uptake of paclitaxel and oxaliplatin, respectively, may have the potential to protect against CIPN. The ability of dasatinib inhibition of OCT2 to prevent oxaliplatin-induced peripheral neuropathy in patients with colorectal cancer $[74,75]$ is currently being evaluated in a clinical trial (ClinicalTrial. gov identifier: NCT04164069; open to recruitment at the time of writing).

The impact of PNS and CNS neuroinflammatory and neuroimmune processors on CIPN are being increasingly considered [37, 57, 76]. Many chemotherapeutic compounds, including paclitaxel, increase the serum levels of cytokines and monocytes in patients [77, 78] and pre-clinical CIPN models. Evidence suggests that chemotherapeutic agents alter both the innate and adaptive immune responses. This results in increased proinflammatory immune cells, dysregulation of Schwann cells $[63,79]$ and activation of DRG satellite glial cells, which release cytokines and further unbalance inflammation [37]. Modulation of many immune and inflammatory processors reduces pain behaviours in pre-clinical CIPN models. Tolllike receptors (TLR), which are expressed on immune cells and play a critical role in the innate immune system, are also expressed on DRG neurons, where they are thought to regulate sensory functions $[80,81]$. TLR- 4 expression in DRGs is increased as paclitaxel-induced CIPN develops [82] and is thought to promote macrophage infiltration. Interestingly, TLR4 antagonists can prevent the development of paclitaxel-induced pain behaviours [81]. The preclinical evidence supports the theory that the inflammatory and immune systems are involved in CIPN development. The role of these systems in other chronic pain conditions [83], together with the immunomodulatory effects that chemotherapies engage to destroy tumours [37], suggests that normalizing chemotherapy-induced immune changes may reduce CIPN and have broad-spectrum therapeutic benefits. In summary, research on the mechanisms underlying CIPN has been robust but there is a need for a more systematic comparison of mechanistic factors contributing to CIPN stimulated by different chemotherapy drugs, administered individually and in combinations commonly used in the clinic [84]. As inflammatory processes and the pain experience are different in males and females [85-88], this work needs to be done in both sexes and validated across various model systems and patient populations. In particular, this should include pre-clinical cancer models, as tumours themselves have immunomodulatory properties that are likely to be relevant $[37,89]$. Current evidence suggests that although divergent mechanisms underlie the development of CIPN, the degenerative pathways they trigger are comparable. Thus, understanding how specific chemotherapy treatments damage peripheral nerves may help identify chemotherapy-specific early interventions that prevent CIPN. Conversely, a clear understanding of the shared degenerative pathways that establish and maintain CIPN could result in effective broad-spectrum therapies that are effective for CIPN, as well as other neuropathies. More research is needed to understand the pathophysiology of cancer treatment-related pain which will likely lead to improved pharmacotherapy.

\section{Current Approaches to the Pharmacotherapy of Chronic Pain in Cancer Survivors}

Choosing the best pain management strategy for a cancer survivor is complex. It is important to take into consideration the potential impact of pain medications on health, physical and mental states, health behaviours, professional and personal identity, sexuality and financial standing.

\subsection{Opioids}

Cancer patients often require initiation of opioid treatment for relief of moderate-severe pain arising during their diagnostic work-up and treatment. However, the role of longterm opioid therapy (LTOT) in cancer survivors, especially those who are disease-free after completing definitive treatment, is unclear. According to some, it raises the same concerns as it does in people with chronic non-malignant pain [5]. Chronic opioid use is also associated with chronic constipation, mental clouding, hypogonadism, effects on sexual desire and fertility, sleep disorders, hyperalgesia, and tolerance, misuse and abuse. Chronic use of opioids by long-term survivors may interfere with employment, family dynamics and personal identity. Possible personal 
implications of chronic opioid use include fear of substance abuse, substance abuse relapse, and the social cost of accepting pain medications during treatment if in a recovery community, especially for survivors who require opioid replacement therapy with buprenorphine or methadone for opioid use disorder (OUD). Key points for using long-term opioid therapy in cancer survivors are summarized in Table 3.

LTOT would not be recommended in cancer survivors who have chronic pain from pre-existing non-malignant comorbidities such as osteoarthritis, spondylosis or migraine because they are considered ineffective for this purpose [7]. Concomitant non-cancer pain is common in cancer survivors [6] and it can be exacerbated by the deconditioning that follows cancer treatment. These patients need a full diagnostic workup using a biopsychosocial approach and should be treated congruent with the etiology of pain. Opioids would only be recommended in patients with moderate-severe pain that has not responded to maximum tolerated doses of nonopioid therapies $[90,91]$.

A recent review of persistent opioid use in cancer survivors has found a relationship between LTOT and various clinical factors including cancer type, socioeconomic factors and comorbidities $[92,93]$. A national survey in the US found that $5 \%$ of opioid prescriptions were for cancer survivors [94]. They were more likely to receive opioids than patients without a cancer history, but they did not have an increased incidence of opioid misuse, which was uncommon, occurring in only $3-4 \%$ of both groups. Risk factors for misuse by cancer survivors included younger age (aged 18-34 years vs $\geq 65$ years) (OR 7.06; 95\% CI $3.03-16.41 ; p<0.001$ ), alcohol use disorder (OR 3.22; 95\% CI $1.45-7.14 ; p=0.005)$ and non-opioid drug use disorder (OR 14.76; 95\% CI 7.40-29.44; $p<0.001$ ) [94]. It is somewhat controversial whether opioid misuse in chronic pain patients, including cancer survivors, is the same entity as OUD in people who use opioids for non-medical purposes. An alternative term, complex persistent opioid dependence (CPOD), is preferred by some to describe this diagnostic entity, which is hard to diagnose by the DSM-V criteria for OUD [95]. CPOD has the same underlying mechanism and responds to the same treatment, with opioid replacement therapy [95]. When opioid misuse does occur in a cancer survivor, it can present a very challenging management problem [96].

Overdose is the most feared consequence of opioid use. It has been increasing not only in the general population but also among cancer patients [97]. Furthermore, co-involvement of alcohol and/or benzodiazepines in these deaths is common and increasing, reaching $14.7 \%$ for alcohol and $21.0 \%$ for benzodiazepines in one recent study [98]. Reducing the concomitant use of these agents provides a potential target for policy and practice efforts to reduce opioid-related harms.

Opioid diversion (defined as unlawful channelling of opioids from the patient for whom they were prescribed to others) is also a risk with long-term opioid use, even in cancer survivors. Unused prescription opioids are the primary source of misuse among family members, as well as the community at large [93]. Among family members with OUD, $70 \%$ began taking opioids prescribed to a relative and only $30 \%$ obtained their drugs of addiction from other sources [99]. However, prescribers do need to take ownership of opioid diversion: the study also showed that for those at the highest risk of overdose-people who use prescription opioids nonmedically 200 or more days a year-the most common way they get opioids is through their own prescriptions ( $27 \%$ of the time), as often as they get the drugs from friends or family for free (26\%) or buy them from friends (23\%).

Given all these problems, the decision to continue or restart opioids after completing cancer treatment should not be made lightly. When opioids are necessary, the lowest effective dose should be prescribed and as the painful condition resolves, opioids should be tapered down or discontinued in a safe manner.

\subsubsection{Reducing or Discontinuing Opioids}

In cancer survivors who have been taking opioids for years, tapering may need to be done over a prolonged

Table 3 Long-term opioid therapy (LTOT) in disease-free cancer survivors: key points

The role of LTOT is unclear

The main indication is moderate-severe treatment-related pain not responding to maximally tolerated therapy with non-opioid approaches

Opioids that were initiated during cancer treatment should be tapered off in survivors. This should be done gradually to avoid pain exacerbation and other adverse events (depression, suicide, illicit drug use, accidental overdose)

LTOT is not normally recommended for comorbid chronic non-malignant pain, which is common in cancer survivors

If LTOT is indicated in cancer survivors, it needs the same close monitoring as for patients with chronic non-malignant pain

Although opioid misuse by people with chronic pain may be distinguished from opioid use disorder seen with recreational drug use, the patho-

physiologic mechanisms are similar and the treatment the same, with opioid replacement therapy

Risk factors for misuse are young age (under 35 years) and personal history of substance abuse

Risk factors for opioid overdose include prolonged use and concomitant alcohol and benzodiazepine use 
period-weeks to months or longer. If withdrawal symptoms prevent further dose decrease, the taper should be temporarily halted and resumed when the withdrawal symptoms decrease, and with close monitoring. Observational data suggests that serious harms such as opioid overdose and suicidal ideation can occur following opioid dose reduction or discontinuation, but the incidence of these harms at the population level is unknown [100]. Referral to an addiction specialist, primary care provider or clinic who can prescribe opioid replacement therapy may be helpful for long-term management of OUD or CPOD in a cancer survivor, and new approaches to the transitioning of treatment are being developed [101].

\subsubsection{Monitoring of Long-Term Opioid Therapy}

Realistic goals, agreement about safe usage, storage and disposal and frequent reassessment are paramount if opioid therapy is considered for a cancer survivor. Realistic goals include functional pain management outcomes and creation of a strategy to avoid/ minimize the risks related to opioids. Treatment needs to be re-evaluated if treatment goals or safety goals are not met.

- Establish and document desirable functional outcomes.

- Re-evaluate the effectiveness and necessity of opioids on a regular basis.

- If the expected outcome is not achieved, other treatment alternatives should be considered. If opioids are no longer appropriate, recommend gradual tapering of opioids to help avoid symptoms of withdrawal.

- Consider establishing pain treatment agreements.

- Adjuvant medications and non-pharmacological interventions should be considered.

- Use a multimodality approach to pain management if warranted, and if those resources are available. Consider referral to a specialist in interventional pain, physical medicine and rehabilitation, or other appropriate consultants.

- It is important to be aware that pain experience in a cancer survivor can be influenced by both medical and psychosocial events during and after cancer treatment. Psychological support of the survivor with chronic pain is necessary, and referral to psychosocial services should be considered.

\subsubsection{Overcoming Barriers to Long-Term Opioid Therapy When It is Clinically Appropriate}

Cancer patients are generally excluded from various guidelines suggesting limiting chronic opioid prescribing (https:// www.cdc.gov/drugoverdose/pdf/prescribing/Guidelines Factsheet-a.pdf (last accessed May 22, 2021). In the US, however, $92 \%$ of US oncology practices are concerned that restrictions on opioid prescribing to non-cancer pain patients will result in undertreating cancer pain (American Society of Clinical Oncology. 2017 Oncology Practice Census [102]). About $40 \%$ of the oncology practices in the US report new barriers to patients receiving opioids in the pharmacy [102]. If chronic opioids are indicated, the prescriber should provide administrative support to the cancer survivor to ensure appropriate access to opioids.

\subsubsection{Opioids and Pregnancy}

If a survivor on LTOT is pregnant or wants to become pregnant, opioids should not be stopped abruptly. Safe pain management should be coordinated with the obstetrician. If the pregnant survivor has OUD and takes buprenorphine for addiction and/or pain, the opioid prescriber should provide access to addiction services without stopping buprenorphine.

\subsection{Adjuvant Analgesics}

Adjuvant analgesics are defined as medications with other primary indications that possess analgesic properties under certain circumstances. They are integral components in all three steps of the WHO analgesic ladder for treatment of cancer pain, and utilization of adjuvant agents in cancer patients has been demonstrated to correlate with improvement in cancer-related pain, anxiety and depression, and lower opioid doses [103]. They are now often prescribed as first-line or monotherapy, rather than as an add-on to opioid therapy, and they are recommended before opioids in the management of cancer treatment-related pain [8].

Common adjuvant analgesics include paracetamol, non-steroidal anti-inflammatory drugs (NSAIDs), selected antidepressants, anticonvulsants, N-methyl-D-aspartate (NMDA) receptor antagonists and steroids. Other agents such as local anaesthetics, benzodiazepines, $\alpha 2$-agonists (e.g. clonidine or tizanidine), bisphosphonates, monoclonal antibodies or topical agents also play a role in treating specific pain conditions. The evidence base for the systemic administration of these agents in cancer survivors is summarized in Table 4.

\subsubsection{Anti-inflammatory Agents}

The ASCO Guideline on pain in cancer survivors recommends prescribing non-opioid analgesics such as paracetamol (acetaminophen) and NSAIDs for chronic treatmentrelated pain [8]. These agents will be expected to be most effective for the nociceptive pain syndromes (see Table 1) as well as comorbid chronic non-malignant pain such as spondylosis or osteoarthritis, which are often aggravated by cancer treatment. A recent systematic review of randomized 
controlled trials (RCTs) on NSAIDs in cancer pain included one RCT where $73 \%$ of participants were breast cancer survivors. They were randomized to receive celecoxib $200 \mathrm{mg}$ twice daily or diclofenac $50 \mathrm{mg}$ twice daily for 6 weeks. While the primary outcome was mood (celecoxib was more of an antidepressant), both groups experienced an approximately $25 \%$ reduction in pain, from a baseline of around $6 / 10$ to around $4.5 / 10$ [104].

Given the inflammatory basis of checkpoint inhibitor toxicity, a stepwise escalation of rheumatological therapy has been recommended for patients with painful complications not responding to NSAIDs. The first step is local or systemic glucocorticoids (e.g. prednisone) followed by disease-modifying antirheumatic drugs. Severe myositis can be life-threatening and requires a high dose of glucocorticoids and close monitoring. In the case of patients with preexisting rheumatic disease on immunosuppressive treatment who need to be treated with checkpoint inhibitors for cancer, it is recommended to maintain their baseline treatment at the lowest effective dose before starting immunotherapy [43].

\subsubsection{Antidepressants}

Antidepressants are used for cancer treatment-related neuropathic pain, most commonly tricyclic antidepressants (TCA), selective serotonin reuptake inhibitors (SSRI) and serotonin noradrenaline reuptake inhibitors (SNRI). Their use is largely guided by studies on non-selective neuropathic pain conditions. A highly cited systematic review of pharmacotherapy for neuropathic pain in adults from a few years ago recommended antidepressants as first-line agents for neuropathic pain in adults [105]. The primary outcome measure in the review was a $50 \%$ reduction in pain score (when this was not available, a 30\% reduction or at least moderate pain relief were used as surrogates). The quality of the evidence using the GRADE criteria was high for SNRI and moderate for TCA. SNRI had a number-neededto-treat (NNT) of 6.4 (95\% CI 5.2-8.4) while TCA had an NNT of 3.6 (95\% CI 3.0-4.4). For both SNRI and TCA, the NNT was lower than the number-needed-to-harm (11.8 and 13.4, respectively), indicating a favourable risk-benefit profile [105].

In terms of cancer survivor pain specifically, there have been specific studies of antidepressants for painful CIPN, with only the SNRI agent duloxetine being specifically recommended by the American Society of Clinical Oncology [8]. This is based on results of two RCTs of duloxetine at doses of up to $60 \mathrm{mg}$ daily $[106,107]$. At least $30 \%$ reduction in baseline pain score was achieved in $38 \%$ and $73 \%$ of patients in the duloxetine arms of the two studies, and $11 \%$ and $18 \%$ in the two control arms, leading to NNTs of 3.7 and 1.6, respectively. Fatigue (7\%), insomnia (5\%) and nausea (5\%) were the most common adverse effects reported by

Table 4 Summary of evidence from controlled clinical trials for systemic adjuvant analgesics in cancer survivors ${ }^{\mathrm{a}}$

\begin{tabular}{|c|c|c|c|c|c|c|}
\hline Drug class [references] & $\begin{array}{l}\text { Drugs, daily dose (mg/ } \\
\text { day), duration }\end{array}$ & Pain syndrome & $\begin{array}{l}\text { Number } \\
\text { in study }\end{array}$ & $\begin{array}{l}\text { Mean pre-post } \\
\text { reduction in pain } \\
\text { score/10 }\end{array}$ & $\begin{array}{l}\text { Percentage with } \\
\text { reduced pain } \\
\text { score }\end{array}$ & NNT \\
\hline $\begin{array}{l}\text { Non-steroidal anti-inflam- } \\
\text { matory drugs [104] }\end{array}$ & $\begin{array}{l}\text { Celecoxib } 400 \mathrm{mg} \text { vs } \\
\text { diclofenac } 100 \mathrm{mg}, \\
6 \text { weeks }\end{array}$ & $\begin{array}{l}\text { Breast cancer survivors, } \\
\text { post-chemotherapy or } \\
\text { radiation therapy }\end{array}$ & 53 & 1.4 vs 1.5 & & \\
\hline \multirow[t]{2}{*}{$\begin{array}{l}\text { Tricyclic antidepressants } \\
{[110,111]}\end{array}$} & $\begin{array}{l}\text { Amitriptyline } 10-50 \mathrm{mg} \text { vs } \\
\text { placebo, } 7 \text { weeks }\end{array}$ & CIPN & 44 & 3.4 vs 1.9 & & \\
\hline & $\begin{array}{l}\text { Nortriptyline } 100 \mathrm{mg} \text { vs } \\
\text { placebo, } 4 \text { weeks }\end{array}$ & CIPN & 51 & 0.7 vs 0.3 & 69 vs $27 \%$ & 2.4 \\
\hline \multirow{3}{*}{$\begin{array}{l}\text { Serotonin-norepinephrine } \\
\text { reuptake inhibitors [106, } \\
109,113 \text { ] }\end{array}$} & $\begin{array}{l}\text { Duloxetine } 60 \mathrm{mg} \text { vs } \\
\text { placebo, } 5 \text { weeks }\end{array}$ & CIPN & 231 & 0.7 vs 0.3 & 59 vs $38 \%$ & 4.8 \\
\hline & $\begin{array}{l}\text { Duloxetine } 60 \mathrm{mg} \text { vs } \\
\text { placebo, } 12 \text { weeks }\end{array}$ & AIMSS & 255 & 2.8 vs 2.0 & 68 vs $59 \%$ & 11 \\
\hline & $\begin{array}{l}\text { Venlafaxine } 75 \mathrm{mg} \text { vs } \\
\text { placebo, } 10 \text { weeks }\end{array}$ & Post-mastectomy pain & 13 & 4.9 vs 4.8 & & \\
\hline Gabapentinoids [117] & $\begin{array}{l}\text { Gabapentin up to } 2700 \mathrm{mg} \\
\text { vs placebo, } 6 \text { weeks }\end{array}$ & CIPN & 115 & 1.0 vs 0.6 & & \\
\hline $\begin{array}{l}\text { Medicinal cannabis prod- } \\
\text { ucts [139] }\end{array}$ & $\begin{array}{l}\text { Nabiximols, up to } 32.4 \mathrm{mg} \\
\text { THC vs placebo, } 4 \text { weeks }\end{array}$ & CIPN & 16 & 0.75 vs 0.37 & 31 vs $0 \%$ & \\
\hline
\end{tabular}

AIMSS aromatase inhibitor musculoskeletal syndrome, CIPN chemotherapy-induced peripheral neuropathy, $N N T$ number needed to treat, $T H C$ tetrahydrocannabinol

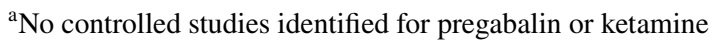


patients treated with duloxetine, but was no different to the placebo arm [106]. There has not been a study of venlafaxine for established CIPN, although it has been shown to be effective for acute neurotoxicity from oxaliplatin [108]; however, there is small, older RCT of low-dose venlafaxine $(18.75 \mathrm{mg}$ daily) versus placebo for persistent pain after breast cancer surgery [109]. The study found no difference in the average daily pain score (primary outcome) but average pain relief and maximum pain intensity were significantly lower in the intervention group. Anxiety and depression were not affected, and adverse effects did not show significant differences between treatments. The evidence for tricyclic antidepressants in CIPN is considered inconclusive, based on two old studies showing no benefit for amitriptyline up to $50 \mathrm{mg}$ per day in one RCT [110] and limited evidence in favour of nortriptyline up to $100 \mathrm{mg}$ per day in the other [111], although these doses were generally well tolerated.

Duloxetine has also been evaluated in AIMSS, and showed decreases in AIMSS symptoms in two patients out of three, although some patients experienced intolerable adverse effects [112]. Specifically, a large multi-site RCT compared duloxetine $60 \mathrm{mg}$ for 12 weeks versus placebo in 255 patients [113]. By the primary endpoint at 12 weeks, more patients (68 vs 59\%) receiving duloxetine had a reduction in pain score of $\geq 2$ points but the difference was not significant. Again, the most common any-grade adverse events in the duloxetine arm were fatigue (32\%) and nausea (30\%), with dry mouth (25\%) and headache (21\%) also common [118].

\subsubsection{Anticonvulsants}

Anticonvulsants are also frequently used against cancer treatment-related neuropathic pain, again extrapolating significant evidence from treatment of non-malignant conditions [105]. Gabapentin and pregabalin exert their effect through modulation of calcium channels [114], while phenytoin, lamotrigine and carbamazepine suppress ectopic discharge by inhibiting sodium channels [115]. In a systematic review of CIPN [116], it was concluded that the evidence does not support the use of gabapentinoids or lamotrigine for this indication. One older, well designed but negative RCT was included, with gabapentin given for 6 weeks to a target dose of $2700 \mathrm{mg} /$ day [117]. There were no studies of pregabalin. Drowsiness, headache and somnolence are common limitations for this class of adjuvant analgesics in the cancer population [118].

\subsubsection{NMDA Receptor Antagonists}

Ketamine has been increasingly used for refractory cancer pain and is considered 'third line' for other chronic pain
[119]. Infusions of ketamine have been shown to be effective in pre-clinical CIPN models [120], but has not been evaluated for clinical neuropathic pain in cancer survivor pain in humans [121]. Limitations to using ketamine include concerns for hypertension and neuropsychiatric side effects [122], and its limited modes of delivery, and high heterogeneity from existing studies that resulted in insufficient evidence for its efficacy have precluded its widespread routine use [119, 123]. More recently, there has been renewed interest in investigating its sublingual/oral route for improved accessibility and a study addressing its role in cancer-related breakthrough pain is currently underway (ANZCTR ID: ACTRN12621000328875).

Magnesium is a nutrient with NMDA receptor antagonist activity and additional effects on muscle relaxation and antiinflammatory mechanisms that has gained popularity due to its relative inexpensiveness and safety profile, despite inconclusive evidence on efficacy to date [124, 125]. Studies are also underway for its wider application in managing cancerrelated pain, including in the prevention of post-mastectomy syndrome [126].

In summary, the ASCO expert panel on cancer survivor pain acknowledged that "NMDA antagonists are taken by some cancer survivors with chronic pain and may benefit some of those who receive them. However, the efficacy of these agents and their long-term effectiveness have not been established" (Recommendation 2.5, Qualifying Statement) [8].

\subsubsection{Topical Analgesics}

Several RCTs have demonstrated variable benefits with topical agents in various acute and chronic pain syndromes in cancer survivors. These include doxepin mouthwash for acute radiation-induced mucositis [127], high-dose capsaicin $8 \%$ patch [128] or amitriptyline cream for CIPN neuropathy $[129,130]$ and capsaicin cream [131] or lignocaine transdermal patches for post-surgical pain [132-134]. However, heterogeneity of the studies warrants clinical discretion when making treatment decisions in individual patients.

\subsection{Cannabinoids}

Cannabis sativa contains a multitude of phytocannabinoids, such as the psychoactive constituent $\Delta$ 9-tetrahydrocannabinol (THC), plus other constituents such as cannabidiol (CBD) that do not produce THC-like psychotropic side effects. Agonism at $\mathrm{CB} 1$ and $\mathrm{CB} 2$ receptors by cannabis-based medicines have shown analgesia in rodent models of neuropathic pain [135]. Cancer patients have reported favourable outcomes for managing chemotherapy-induced nausea and vomiting as well as symptoms 
due to cancer such as pain [136], but there are differing views as to their clinical efficacy and safety in light of the limited number of high-quality clinical trials evaluating these benefits being currently available [137, 138]. We located one study specifically addressing the safety and efficacy of cannabinoids in cancer survivors, a small $(n=16)$ placebo-controlled RCT of nabixomols-an oromucosal spray with a plant-derived combination of THC and CBD-at a maximum dose of 12 sprays $(32.4 \mathrm{mg}$ THC) per day for chemotherapy-induced polyneuropathy [139]. There was a small positive effect size for achieving a $50 \%$ reduction in pain $(0.11)$ in favour of cannabis over placebo, but it was not statistically significant $(95 \%$ CI -0.06 to 0.28$)$. Five (31\%) of the nabixomols group were considered 'responders', with an average reduction of numeric rating scale for pain of 2.6. This study is included in a Cochrane review of the efficacy, tolerability and safety of cannabis for neuropathic pain [140]. The review included 16 studies with 1750 participants. It showed that cannabis-based medicines may increase the number of people achieving pain relief of $30 \%$ or greater compared with placebo (39 vs 33\%; NNT 11 [95\% CI 7-33]; moderate quality evidence). However, any potential benefits of cannabis-based medicine in chronic neuropathic pain might be outweighed by their potential harms, as they increased nervous system adverse events with a number needed to harm (NNTH) of only 3 (95\% CI 2-6) and psychiatric disorders with a NNTH of 10 , occurring in 17 vs $5 \%$.

We also found one systematic review on the opioidsparing effects of cannabis in non-cancer chronic pain [141]. Nine studies involving 7222 participants were included, but all were observational studies and only one had a control group [142]. This study evaluated the magnitude of associations between enrolment in the New Mexico Medical Cannabis Program (MCP), opioid prescription use and pain-related outcomes, when compared with an historical control before the program started. They found clinically and statistically significant evidence of an association between MCP enrolment and opioid prescription cessation, opioid dose reduction and improved quality of life [142]. The study design does not, however, allow for any causal inferences about MCP enrolment and the observed outcomes to be made.

We did find a qualitative study analysing interviews in 33 Canadian cancer survivors using the broad definition of survivorship (from diagnosis until the end of their life) [143]. All 33 survivors believed that cannabis would relieve their symptoms, but only 17 (approximately half) were currently using it. Reasons given for using it were that it was a "more natural alternative" to prescription medications; it helped reduce polypharmacy because it was effective for multiple symptoms; and that the legalization of recreational use implied that 'safer products' must now be available. Those who chose not to use it were deterred by the lack of evidence and the risk of dependency. The attitudes of their physician, family and friends towards medicinal cannabis was also a factor in their decision making.

\subsection{New Drugs}

While new formulations of old drugs have been approved, very few truly novel analgesics have been approved by the US Food and Drug Administration or other regulatory agencies in recent decades. The opioid epidemic is leading to renewed interest in finding new targets [144]. Novel opioids, $\alpha$-adrenergic agonists and oxytocin have been identified as potential candidates, along with target toxins and gene-based approaches such as protein synthesis blockade and transfection [144, 145]. With regard to cancer treatmentrelated pain specifically, novel agents are being evaluated for CIPN. MR309, an oral sigma 1 antagonist (sigma-1 is a mitochondrial endoplasmic reticulum receptor), has been shown to reduce chemotherapy-induced mitochondrial structural changes and pain behaviours in lab animals [146]. A randomized phase II clinical trial of MR309 was shown to improve short-term outcomes (decreased cold hypersensitivity) in patients receiving oxaliplatin-based chemotherapy, reducing treatment dropouts and allowed a higher cumulative dose of oxaliplatin to be given [147]. However, its effect on chronic pain outcomes is unknown.

\section{Nonpharmacological Approaches}

Various organizations including ASCO and National Comprehensive Cancer Network (NCCN) recommend a combination of pharmacologic and non-pharmacologic modalities for managing chronic pain in cancer survivors $[2,8]$. Non-pharmacological strategies include neuromodulation, complementary and alternative medicine, and psychosocial interventions.

\subsection{Neuromodulation}

Transcutaneous electrical nerve stimulation (TENS) uses electrical fields to active motor or sensory fibres, which in turn inhibit the spinothalamic system and minimize pain sensation (the gate control theory) [148]. TENS is a reasonable 
option for patients who have focal pain. It has been shown to improve pain control for breast cancer patients and function for various cancer patients as a goal-directed therapy $[149,150]$. Specialized devices have shown efficacy in CIPN [151]. Limitations to broad adoption of TENS units (cumbersome, decreased usage over time and transient effects) have led to development of more precise and implanted systems [149] such as peripheral nerve stimulation (PNS) and spinal cord stimulation (SCS).

By implanting a stimulator closer to a nerve, the skin is bypassed as a resistor, and thus PNS can preferentially activate fast-acting sensory fibres, creating comfortable sensations that indirectly inhibit pain signals [152]. PNS devices have been shown to be helpful in treating post-mastectomy pain syndrome and chronic radiation- and surgical resection-related neuropathies [152]. SCS primarily works by stimulating the dorsal columns to inhibit transmission of pain signals [153]. Patients with focal pain and an intact epidural space may benefit from these devices. SCS has been used for cancer treatment pain such as radiation neuritis and chemotherapy-induced peripheral neuropathy [154].

\subsection{Psychological Therapy for Chronic Pain in Cancer Survivors}

Chronic pain, whether related to cancer treatment or otherwise, is a multidimensional phenomenon that benefits from being assessed and managed within a biopsychosocial framework [155-158]. For example, high levels of preoperative anxiety, depression, distress and catastrophizing were predictive of post-operative pain at all time points up to 12 months and beyond in women with early-stage breast cancer [158]. In cancer survivors, there is strong evidence that depression and anxiety are associated with increased pain and higher levels of physical activity are associated with lower levels of pain [156]. Likewise, loneliness, fatigue and sleep problems are all associated with greater pain in this group.

Psychological interventions to address these feelings could in turn influence levels of pain and pain's interference with function by reducing distress, improving sleep and increasing activity levels and function. Although they are not aimed at pain reduction per se, all of these outcomes can serve to reduce pain levels. Unfortunately, because of limited access to and/or reimbursement of psychological treatments in many countries, treatment for pain in cancer survivors still tends to be primarily biomedical, and assessment is not routinely conducted within a biopsychosocial framework. This situation persists despite mounting evidence that a range of psychological and behavioural interventions can reduce pain severity and pain interference in patients with cancer, as they do in patients with chronic pain from the wider population.
Psychological and behavioural approaches have been shown to reduce cancer pain at diagnosis and during treatment [156]. However, there is far less research available on the psychological and behavioural aspects of survivor pain and related interventions. Strategies that have been evaluated include exercise programmes with group and cognitive behavioural therapy (CBT) elements. CBT in this context refers to a range of skills and behaviours including cognitive training to reframe pain-related catastrophic cognitions, using adaptive behaviours such as engaging in distraction, pacing and planning activities, relaxation, imagery, exercise and yoga [156]. Education may include CBT elements that address barriers to engagement in treatment and that assist in effective communication with healthcare providers, particularly about pain. All of the above can also be useful in assisting partners and caregivers to respond to pain and painrelated distress in a manner that will help reduce these [156].

\subsection{Complementary and Alternative Medicine}

Once carefully incorporated into standard care, complementary and alternative medicine (also known as integrative medicine) therapies can complement other treatments and enhance the quality of care that survivors with chronic pain are receiving. Most of the current research data comes from studies of mind-body practice, acupuncture, massage therapy and music therapy, and data from RCTs support the effect of hypnosis, acupuncture and music therapy in reduction of pain [159]. Mindfulness meditation, yoga, qigong and massage therapy have not been shown to reduce pain per se but can relieve the emotional distress that is commonly associated with pain. One expert in the field recommends considering the burdens and risks to patients, patient preference and the presence or absence of better alternatives when making decisions on whether an integrative medicine therapy is of clinical value [159].

\section{Conclusion}

Millions of people are living with chronic pain after completing cancer treatment and the number continues to grow as improvements in cancer treatment continue to be developed. While opioids are the mainstay of pain due to cancer, their use is problematic in disease-free cancer survivors who have been treated with curative intent and have a normal prognosis. If these people have chronic pain, other treatment options should be tried first. While we have summarized here the latest information on non-opioid drugs that can be prescribed, including adjuvant analgesics, medicinal cannabis products, and investigational agents, it must be recognized that a multidimensional approach is needed for the optimal 
management of chronic pain, with non-pharmacologic interventions being provided alongside pharmacologic ones.

\section{Declarations}

Funding This manuscript was not funded; the time and effort of the authors was contributed by their employers.

Conflict of interest P. Glare was previously a Medical Advisor for Cymra Life Sciences. A. Gulati is a Consultant for Medtronic, Flowonix, SPR therapeutics, Nalu Medical, Tremeau Medical and is a Medical Advisor for AIS HealthCare and Spark Medical. None of the other authors has any conflicts of interest.

Author contributions All authors contributed to writing the manuscript and reviewed and approved the final manuscript.

Ethics approval and informed consent Not applicable.

Data availability Not applicable.

Open Access This article is licensed under a Creative Commons Attribution-NonCommercial 4.0 International License, which permits any non-commercial use, sharing, adaptation, distribution and reproduction in any medium or format, as long as you give appropriate credit to the original author(s) and the source, provide a link to the Creative Commons licence, and indicate if changes were made. The images or other third party material in this article are included in the article's Creative Commons licence, unless indicated otherwise in a credit line to the material. If material is not included in the article's Creative Commons licence and your intended use is not permitted by statutory regulation or exceeds the permitted use, you will need to obtain permission directly from the copyright holder. To view a copy of this licence, visit http://creativecommons.org/licenses/by-nc/4.0/.

\section{References}

1. Siegel RL, et al. Cancer statistics, 2021. CA Cancer J Clin. 2021;71(1):7-33.

2. Sanft T, et al. NCCN guidelines Insights: survivorship, version 2.2019. J Natl Compr Canc Netw. 2019;17(7):784-94.

3. Glare P, Overton S, Aubrey K. Transition from acute to chronic pain: where cells, systems and society meet. Pain Manag. 2020;10(6):421-36.

4. Portenoy RK, Lesage P. Management of cancer pain. Lancet. 1999;353(9165):1695-700.

5. Farquhar-Smith P, Brown MRD. Persistent pain in cancer survivors: pathogenesis and treatment options. In: PAIN clinical updates. IASP; 2016. p. 1-7.

6. Posternak V, et al. Differences in demographic, clinical, and symptom characteristics and quality of life outcomes among oncology patients with different types of pain. Pain. 2016;157(4):892-900.

7. Chou R, et al. The effectiveness and risks of long-term opioid therapy for chronic pain: a systematic review for a National Institutes of Health Pathways to Prevention Workshop. Ann Intern Med. 2015;162(4):276-86.

8. Paice JA, et al. Management of chronic pain in survivors of adult cancers: American Society of Clinical Oncology Clinical Practice guideline. J Clin Oncol. 2016;34(27):3325-45.
9. Glare PA, et al. Pain in cancer survivors. J Clin Oncol. 2014;32(16):1739-47.

10. Brown M, Farquhar-Smith P. Pain in cancer survivors; filling in the gaps. Br J Anaesth. 2017;119(4):723-36.

11. Paice JA. Pain in cancer survivors: how to manage. Curr Treat Options Oncol. 2019;20(6):48.

12. Stone AL, et al. Topical review: pain in survivors of pediatric cancer: applying a prevention framework. J Pediatr Psychol. 2018;43(3):237-42.

13. Bennett MI, et al. Standards for the management of cancerrelated pain across Europe-a position paper from the EFIC Task Force on Cancer Pain. Eur J Pain. 2019;23(4):660-8.

14. Stinson J, et al. Review of systematic reviews on acute procedural pain in children in the hospital setting. Pain Res Manag. 2008;13(1):51-7.

15. Boland EG, Ahmedzai SH. Persistent pain in cancer survivors. Curr Opin Support Palliat Care. 2017;11(3):181-90.

16. Denk F, McMahon SB, Tracey I. Pain vulnerability: a neurobiological perspective. Nat Neurosci. 2014;17(2):192-200.

17. Roberts K, et al. Management of aromatase inhibitor induced musculoskeletal symptoms in postmenopausal early breast cancer: a systematic review and meta-analysis. Crit Rev Oncol Hematol. 2017;111:66-80.

18. Braar J, Chen GH, Gulati A, et al. Radiation-induced pain syndromes. In: Gulati A, et al., editors. Essentials of interventional cancer pain management. Cham: Springer Nature; 2019.

19. Glare P, Aubrey KR, Myles PS. Transition from acute to chronic pain after surgery. Lancet. 2019;393(10180):1537-46.

20. Meretoja TJ, et al. Clinical prediction model and tool for assessing risk of persistent pain after breast cancer surgery. J Clin Oncol. 2017;35(15):1660-7.

21. Wang L, et al. Predictors of persistent pain after breast cancer surgery: a systematic review and meta-analysis of observational studies. CMAJ. 2016;188(14):E352-61.

22. Lotsch J, et al. Machine-learning-derived classifier predicts absence of persistent pain after breast cancer surgery with high accuracy. Breast Cancer Res Treat. 2018;171(2):399-411.

23. Gupta R, Van de Ven T, Pyati S. Post-thoracotomy pain: current strategies for prevention and treatment. Drugs. 2020;80(16):1677-84.

24. Gane EM, et al. Prevalence, incidence, and risk factors for shoulder and neck dysfunction after neck dissection: a systematic review. Eur J Surg Oncol. 2017;43(7):1199-218.

25 . Jin J, et al. Prevalence and predictors of chronic postsurgical pain after colorectal surgery: a prospective study. Colorectal Dis. 2021;23(7):1878-89. https://doi.org/10.1111/codi.15640.

26. Alper I, Yuksel E. Comparison of acute and chronic pain after open nephrectomy versus laparoscopic nephrectomy: a prospective clinical trial. Medicine (Baltimore). 2016;95(16):e3433.

27. Staff NP, et al. Chemotherapy-induced peripheral neuropathy: a current review. Ann Neurol. 2017;81(6):772-81.

28. Seretny M, et al. Incidence, prevalence, and predictors of chemotherapy-induced peripheral neuropathy: a systematic review and meta-analysis. Pain. 2014;155(12):2461-70.

29. Molassiotis A, et al. Risk factors for chemotherapy-induced peripheral neuropathy in patients receiving taxane- and platinumbased chemotherapy. Brain Behav. 2019;9(6):e01312.

30. Shah A, et al. Incidence and disease burden of chemotherapyinduced peripheral neuropathy in a population-based cohort. J Neurol Neurosurg Psychiatry. 2018;89(6):636-41.

31. Bennett MI, et al. The IASP classification of chronic pain for ICD-11: chronic cancer-related pain. Pain. 2019;160(1):38-44.

32. Yan $\mathrm{M}$, et al. The radiation dose tolerance of the brachial plexus: a systematic review and meta-analysis. Clin Transl Radiat Oncol. 2019;18:23-31. 
33. Eblan MJ, et al. Brachial plexopathy in apical non-small cell lung cancer treated with definitive radiation: dosimetric analysis and clinical implications. Int J Radiat Oncol Biol Phys. 2013;85(1):175-81.

34. Lalla RV, et al. Oral complications at 6 months after radiation therapy for head and neck cancer. Oral Dis. 2017;23(8):1134-43.

35. Lind $\mathrm{H}$, et al. Late symptoms in long-term gynaecological cancer survivors after radiation therapy: a population-based cohort study. Br J Cancer. 2011;105(6):737-45.

36. Frey A, et al. Prevalence and predicting factors for commonly neglected sexual side effects to external-beam radiation therapy for prostate cancer. J Sex Med. 2017;14(4):558-65.

37. Lees JG, et al. Immune-mediated processes implicated in chemotherapy-induced peripheral neuropathy. Eur J Cancer. 2017;73:22-9.

38. Stubblefield MD, Keole N. Upper body pain and functional disorders in patients with breast cancer. PM R. 2014;6(2):170-83.

39. Henry NL, et al. Predictors of aromatase inhibitor discontinuation as a result of treatment-emergent symptoms in early-stage breast cancer. J Clin Oncol. 2012;30(9):936-42.

40. Briot $\mathrm{K}$, et al. Effect of a switch of aromatase inhibitors on musculoskeletal symptoms in postmenopausal women with hormone-receptor-positive breast cancer: the ATOLL (articular tolerance of letrozole) study. Breast Cancer Res Treat. 2010;120(1):127-34.

41. Colleoni M, et al. Extended adjuvant intermittent letrozole versus continuous letrozole in postmenopausal women with breast cancer (SOLE): a multicentre, open-label, randomised, phase 3 trial. Lancet Oncol. 2018;19(1):127-38.

42. Postow MA, Sidlow R, Hellmann MD. Immune-related adverse events associated with immune checkpoint blockade. N Engl J Med. 2018;378(2):158-68.

43. Kostine M, et al. EULAR points to consider for the diagnosis and management of rheumatic immune-related adverse events due to cancer immunotherapy with checkpoint inhibitors. Ann Rheum Dis. 2021;80(1):36-48.

44. Mawardi $\mathrm{H}$, et al. Chronic graft-versus-host disease: current management paradigm and future perspectives. Oral Dis. 2019;25(4):931-48.

45. Inamoto $Y$, et al. Assessment of joint and fascia manifestations in chronic graft-versus-host disease. Arthritis Rheumatol. 2014;66(4):1044-52.

46. Peirs C, Seal RP. Neural circuits for pain: recent advances and current views. Science. 2016;354(6312):578-84.

47. Mills EP, et al. Brainstem pain-control circuitry connectivity in chronic neuropathic pain. J Neurosci. 2018;38(2):465-73.

48. Kuner R, Flor H. Structural plasticity and reorganisation in chronic pain. Nat Rev Neurosci. 2016;18:20.

49. Zhuo M. Neural mechanisms underlying anxiety-chronic pain interactions. Trends Neurosci. 2016;39(3):136-45.

50. Omran M, et al. Review of the role of the brain in chemotherapy-induced peripheral neuropathy. Front Mol Biosci. 2021;8:693133.

51. Burma NE, et al. Animal models of chronic pain: advances and challenges for clinical translation. J Neurosci Res. 2017;95(6):1242-56.

52. Price TJ, et al. Transition to chronic pain: opportunities for novel therapeutics. Nat Rev Neurosci. 2018;19(7):383-4.

53. Weinstein EJ, et al. Local anaesthetics and regional anaesthesia versus conventional analgesia for preventing persistent postoperative pain in adults and children. Cochrane Database Syst Rev. 2018;6:CD007105.

54. Ibrahim EY, Ehrlich BE. Prevention of chemotherapy-induced peripheral neuropathy: a review of recent findings. Crit Rev Oncol Hematol. 2020;145:102831.
55. Li Y, Lustberg MB, Hu S. Emerging pharmacological and nonpharmacological therapeutics for prevention and treatment of chemotherapy-induced peripheral neuropathy. Cancers (Basel). 2021;13(4):766.

56. Zajaczkowska R, et al. Mechanisms of chemotherapy-induced peripheral neuropathy. Int J Mol Sci. 2019;20(6):145.

57. Boyette-Davis JA, et al. An updated understanding of the mechanisms involved in chemotherapy-induced neuropathy. Pain Manag. 2018;8(5):363-78.

58. Jimenez-Andrade JM, et al. Vascularization of the dorsal root ganglia and peripheral nerve of the mouse: implications for chemical-induced peripheral sensory neuropathies. Mol Pain. 2008;4:10.

59. Weaver BA. How taxol/paclitaxel kills cancer cells. Mol Biol Cell. 2014;25(18):2677-81.

60. da Costa R, et al. Taxane-induced neurotoxicity: Pathophysiology and therapeutic perspectives. $\mathrm{Br} \mathrm{J}$ Pharmacol. 2020;177(14):3127-46.

61. Pachman DR, et al. Comparison of oxaliplatin and paclitaxelinduced neuropathy (Alliance A151505). Support Care Cancer. 2016;24(12):5059-68.

62. Arango D, et al. Molecular mechanisms of action and prediction of response to oxaliplatin in colorectal cancer cells. Br J Cancer. 2004;91(11):1931-46.

63. Imai $\mathrm{S}$, et al. Taxanes and platinum derivatives impair Schwann cells via distinct mechanisms. Sci Rep. 2017;7(1):5947.

64. Brandolini L, et al. Chemokine signaling in chemotherapyinduced neuropathic pain. Int J Mol Sci. 2019;20(12):2904.

65. Chukyo A, et al. Oxaliplatin-induced changes in expression of transient receptor potential channels in the dorsal root ganglion as a neuropathic mechanism for cold hypersensitivity. Neuropeptides. 2018;67:95-101.

66. Pereira AF, et al. Neurotoxic effect of oxaliplatin: Comparison with its oxalate-free analogue cis-[PtII(1R,2R-DACH)(3-acetoxy-1,1-cyclobutanedicarboxylato)] (LLC-1402) in mice. Toxicol Appl Pharmacol. 2018;340:77-84.

67. Wozniak KM, et al. Sustained accumulation of microtubulebinding chemotherapy drugs in the peripheral nervous system: correlations with time course and neurotoxic severity. Cancer Res. 2016;76(11):3332-9.

68. Gregg RW, et al. Cisplatin neurotoxicity: the relationship between dosage, time, and platinum concentration in neurologic tissues, and morphologic evidence of toxicity. J Clin Oncol. 1992;10(5):795-803.

69. Dzagnidze A, et al. Repair capacity for platinum-DNA adducts determines the severity of cisplatin-induced peripheral neuropathy. J Neurosci. 2007;27(35):9451-7.

70. Schulte RR, Ho RH. Organic anion transporting polypeptides: emerging roles in cancer pharmacology. Mol Pharmacol. 2019;95(5):490-506.

71. Lancaster CS, et al. Modulation of OATP1B-type transporter function alters cellular uptake and disposition of platinum chemotherapeutics. Mol Cancer Ther. 2013;12(8):1537-44.

72. Leblanc AF, et al. OATP1B2 deficiency protects against paclitaxel-induced neurotoxicity. J Clin Invest. 2018;128(2):816-25.

73. Huang KM, et al. Neuronal uptake transporters contribute to oxaliplatin neurotoxicity in mice. J Clin Invest. 2020;130(9):4601-6.

74. Noonan AM, et al. A phase Ib adaptive study of dasatinib for the prevention of oxaliplatin-induced neuropathy in patients with metastatic colorectal cancer receiving FOLFOX chemotherapy and bevacizumab. J Clin Oncol. 2020;38(15 supp_1):TPS12125.

75. Stage TB, et al. Role for drug transporters in chemotherapy-induced peripheral neuropathy. Clin Transl Sci. 2021;14(2):460-7. 
76. Makker PGS, et al. Characterisation of immune and neuroinflammatory changes associated with chemotherapy-induced peripheral neuropathy. PLoS ONE. 2017;12(1):e0170814.

77. Kober KM, et al. Differential methylation and expression of genes in the hypoxia-inducible factor 1 signaling pathway are associated with paclitaxel-induced peripheral neuropathy in breast cancer survivors and with preclinical models of chemotherapy-induced neuropathic pain. Mol Pain. 2020;16:1744806920936502.

78. Miaskowski C, et al. Perturbations in neuroinflammatory pathways are associated with paclitaxel-induced peripheral neuropathy in breast cancer survivors. J Neuroimmunol. 2019;335:577019.

79. Kober KM, et al. Signaling pathways and gene co-expression modules associated with cytoskeleton and axon morphology in breast cancer survivors with chronic paclitaxel-induced peripheral neuropathy. Mol Pain. 2019;15:1744806919878088.

80. Park HJ, et al. Toll-like receptor signaling regulates cisplatininduced mechanical allodynia in mice. Cancer Chemother Pharmacol. 2014;73(1):25-34.

81. Li Y, et al. Toll-like receptor 4 signaling contributes to paclitaxelinduced peripheral neuropathy. J Pain. 2014;15(7):712-25.

82. Liu XJ, et al. TLR signaling adaptor protein MyD88 in primary sensory neurons contributes to persistent inflammatory and neuropathic pain and neuroinflammation. Sci Rep. 2016;6:28188.

83. Ji RR, Chamessian A, Zhang YQ. Pain regulation by non-neuronal cells and inflammation. Science. 2016;354(6312):572-7.

84. Eldridge S, Guo L, Hamre J 3rd. A comparative review of chemotherapy-induced peripheral neuropathy in in vivo and in vitro models. Toxicol Pathol. 2020;48(1):190-201.

85. McCarthy MM. SexX matters when it comes to pain. Neuron. 2021;109(8):1253-4.

86. Loyd DR, Murphy AZ. The neuroanatomy of sexual dimorphism in opioid analgesia. Exp Neurol. 2014;259:57-63.

87. Shansky RM, Murphy AZ. Considering sex as a biological variable will require a global shift in science culture. Nat Neurosci. 2021;24(4):457-64.

88. Staurengo-Ferrari L, et al. Sexual dimorphism in the contribution of neuroendocrine stress axes to oxaliplatin-induced painful peripheral neuropathy. Pain. 2021;162(3):907-18.

89. Batalha S, Ferreira S, Brito C. The peripheral immune landscape of breast cancer: clinical findings and in vitro models for biomarker discovery. Cancers (Basel). 2021;13(6):1305.

90. Prescription opioids hub: upcoming changes to reduce harm. 2020 [cited 2020]. Available from: https://www.tga.gov.au/node/ 877210.

91. Black E, Khor KE, Demirkol A. Responsible prescribing of opioids for chronic non-cancer pain: a scoping review. Pharmacy (Basel). 2020;8(3):150.

92. Jones KF, et al. Exploring factors associated with long-term opioid therapy in cancer survivors: an integrative review. J Pain Symptom Manag. 2021;61(2):395-415.

93. Jones CM, Paulozzi LJ, Mack KA. Sources of prescription opioid pain relievers by frequency of past-year nonmedical use United States, 2008-2011. JAMA Intern Med. 2014;174(5):802-3.

94. Jairam $\mathrm{V}$, et al. National patterns in prescription opioid use and misuse among cancer survivors in the United States. JAMA Netw Open. 2020;3(8):e2013605.

95. Manhapra A, et al. Complex persistent opioid dependence with long-term opioids: a gray area that needs definition, better understanding, treatment guidance, and policy changes. J Gen Intern Med. 2020;35(Suppl 3):964-71.

96. Loren AW. Harder to treat than leukemia-opioid use disorder in survivors of cancer. N Engl J Med. 2018;379(26):2485-7.

97. Chino F, Kamal A, Chino J. Incidence of opioid-associated deaths in cancer survivors in the United States, 2006-2016: a population study of the opioid epidemic. JAMA Oncol. 2020;6(7):1100-2.

98. Tori ME, Larochelle MR, Naimi TS. Alcohol or benzodiazepine co-involvement with opioid overdose deaths in the United States, 1999-2017. JAMA Netw Open. 2020;3(4):e202361.

99. Welham GC, Mount JK, Gilson AM. Type and frequency of opioid pain medications returned for disposal. Drugs Real World Outcomes. 2015;2(2):129-35.

100. Mackey K, et al. Benefits and harms of long-term opioid dose reduction or discontinuation in patients with chronic pain: a rapid review. J Gen Intern Med. 2020;35(Suppl 3):935-44.

101. Becker WC, Frank JW, Edens EL. Switching from high-dose, long-term opioids to buprenorphine: a case series. Ann Intern Med. 2020;173(1):70-1.

102. Page R, Blanchard E. Opioids and cancer pain: patients' needs and access challenges. J Oncol Pract. 2019;15(5):229-31. https:// doi.org/10.1200/JOP.19.00081.

103. Al-Ansari AM, et al. The pattern of change in opioid and adjuvant prescriptions for cancer pain before and after referral to a comprehensive program in the Palliative Care Center in Kuwait. BMC Palliat Care. 2021;20(1):25.

104. Mohammadinejad P, et al. Celecoxib versus diclofenac in mild to moderate depression management among breast cancer patients: a double-blind, placebo-controlled randomized trial. Ann Pharmacother. 2015;49(9):953-61.

105. Finnerup NB, et al. Pharmacotherapy for neuropathic pain in adults: a systematic review and meta-analysis. Lancet Neurol. 2015;14(2):162-73.

106. Smith EM, et al. Effect of duloxetine on pain, function, and quality of life among patients with chemotherapy-induced painful peripheral neuropathy: a randomized clinical trial. JAMA. 2013;309(13):1359-67.

107. Hirayama Y, et al. Effect of duloxetine in Japanese patients with chemotherapy-induced peripheral neuropathy: a pilot randomized trial. Int J Clin Oncol. 2015;20(5):866-71.

108. Durand JP, et al. Efficacy of venlafaxine for the prevention and relief of oxaliplatin-induced acute neurotoxicity: results of EFFOX, a randomized, double-blind, placebo-controlled phase III trial. Ann Oncol. 2012;23(1):200-5.

109. Tasmuth T, Hartel B, Kalso E. Venlafaxine in neuropathic pain following treatment of breast cancer. Eur J Pain. 2002;6(1):17-24.

110. Kautio AL, et al. Amitriptyline in the treatment of chemotherapy-induced neuropathic symptoms. J Pain Symptom Manag. 2008;35(1):31-9.

111. Hammack JE, et al. Phase III evaluation of nortriptyline for alleviation of symptoms of cis-platinum-induced peripheral neuropathy. Pain. 2002;98(1-2):195-203.

112. Gupta A, Henry NL, Loprinzi CL. Management of aromatase inhibitor-induced musculoskeletal symptoms. JCO Oncol Pract. 2020;16(11):733-9.

113. Henry NL, et al. Randomized, multicenter, placebo-controlled clinical trial of duloxetine versus placebo for aromatase inhibitorassociated arthralgias in early-stage breast cancer: SWOG S1202. J Clin Oncol. 2018;36(4):326-32.

114. McAnally H, Bonnet U, Kaye AD. Gabapentinoid benefit and risk stratification: mechanisms over myth. Pain Ther. 2020;9(2):441-52.

115. Goodwin G, McMahon SB. The physiological function of different voltage-gated sodium channels in pain. Nat Rev Neurosci. 2021;22(5):263-74.

116. Hou S, et al. Treatment of chemotherapy-induced peripheral neuropathy: systematic review and recommendations. Pain Physician. 2018;21(6):571-92.

117. Rao RD, et al. Efficacy of gabapentin in the management of chemotherapy-induced peripheral neuropathy: a phase 3 
randomized, double-blind, placebo-controlled, crossover trial (N00C3). Cancer. 2007;110(9):2110-8.

118. Mitra R, Jones S. Adjuvant analgesics in cancer pain: a review. Am J Hosp Palliat Care. 2012;29(1):70-9.

119. Culp C, Kim HK, Abdi S. Ketamine use for cancer and chronic pain management. Front Pharmacol. 2020;11:599721.

120. Pascual D, et al. Antinociceptive effect of three common analgesic drugs on peripheral neuropathy induced by paclitaxel in rats. Pharmacol Biochem Behav. 2010;95(3):331-7.

121. Orhurhu V, et al. Ketamine infusions for chronic pain: a systematic review and meta-analysis of randomized controlled trials. Anesth Analg. 2019;129(1):241-54.

122. Short B, et al. Side-effects associated with ketamine use in depression: a systematic review. Lancet Psychiatry. 2018;5(1):65-78.

123. Bell RF, Eccleston C, Kalso EA. Ketamine as an adjuvant to opioids for cancer pain. Cochrane Database Syst Rev. 2017;6:CD003351.

124. Kreutzwiser D, Tawfic QA. Expanding role of NMDA receptor antagonists in the management of pain. CNS Drugs. 2019;33(4):347-74.

125. Morel V, et al. Magnesium for pain treatment in 2021? State of the art. Nutrients. 2021;13(5):1397.

126. Morel V, et al. Preventive effect of oral magnesium in postmastectomy pain: protocol for a randomised, double-blind, controlled clinical trial. BMJ Open. 2018;8(9):e017986.

127. Sio TT, et al. Effect of doxepin mouthwash or diphenhydraminelidocaine-antacid mouthwash vs placebo on radiotherapy-related oral mucositis pain: the alliance A221304 randomized clinical trial. JAMA. 2019;321(15):1481-90.

128. Filipczak-Bryniarska I, et al. High-dose $8 \%$ capsaicin patch in treatment of chemotherapy-induced peripheral neuropathy: single-center experience. Med Oncol. 2017;34(9):162.

129. Rossignol J, et al. High concentration of topical amitriptyline for treating chemotherapy-induced neuropathies. Support Care Cancer. 2019;27(8):3053-9.

130. Genevois AL, et al. Analgesic effects of topical amitriptyline in patients with chemotherapy-induced peripheral neuropathy: mechanistic insights from studies in mice. J Pain. 2021;22(4):440-53.

131. Ellison N, et al. Phase III placebo-controlled trial of capsaicin cream in the management of surgical neuropathic pain in cancer patients. J Clin Oncol. 1997;15(8):2974-80.

132. Cheville AL, et al. Use of a lidocaine patch in the management of postsurgical neuropathic pain in patients with cancer: a phase III double-blind crossover study (N01CB). Support Care Cancer. 2009; 17(4):451-60.

133. Aboelnour NH, Abouelnaga WA. Lidocaine iontophoresis for postmastectomy intercostobrachial neuralgia: single-blinded randomized controlled trial. Bull Fac Physical Ther. 2019;24:32-9.

134. Fiorelli A, et al. Preventive skin analgesia with lidocaine patch for management of post-thoracotomy pain: results of a randomized, double blind, placebo controlled study. Thorac Cancer. 2019;10(4):631-41.

135. Mitchell VA, et al. Oral efficacy of Delta(9)-tetrahydrocannabinol and cannabidiol in a mouse neuropathic pain model. Neuropharmacology. 2021;189:108529.

136. Blake A, et al. A selective review of medical cannabis in cancer pain management. Ann Palliat Med. 2017;6(Suppl 2):S215-22.

137. Turgeman I, Bar-Sela G. Cannabis for cancer-illusion or the tip of an iceberg: a review of the evidence for the use of Cannabis and synthetic cannabinoids in oncology. Expert Opin Investig Drugs. 2019;28(3):285-96.

138. Moore RA, et al. Cannabinoids, cannabis, and cannabis-based medicines for pain management: an overview of systematic reviews. Pain. 2021;162(Suppl 1):S67-79.
139. Lynch ME, Cesar-Rittenberg P, Hohmann AG. A double-blind, placebo-controlled, crossover pilot trial with extension using an oral mucosal cannabinoid extract for treatment of chemotherapy-induced neuropathic pain. J Pain Symptom Manag. 2014;47(1):166-73.

140. Mucke M, et al. Cannabis-based medicines for chronic neuropathic pain in adults. Cochrane Database Syst Rev. 2018;3:CD012182.

141. Okusanya BO, et al. Medical cannabis for the reduction of opioid dosage in the treatment of non-cancer chronic pain: a systematic review. Syst Rev. 2020;9(1):167.

142. Vigil JM, et al. Associations between medical cannabis and prescription opioid use in chronic pain patients: a preliminary cohort study. PLoS ONE. 2017;12(11):e0187795.

143. McTaggart-Cowan $\mathrm{H}$, et al. Understanding cancer survivors' reasons to medicate with cannabis: a qualitative study based on the theory of planned behavior. Cancer Med. 2021;10(1):396-404.

144. Volkow ND, Collins FS. The role of science in addressing the opioid crisis. N Engl J Med. 2017;377(4):391-4.

145. Yaksh TL, et al. The search for novel analgesics: targets and mechanisms. F1000Prime Rep. 2015;7:56.

146. Gordon-Williams R, Farquhar-Smith P. Recent advances in understanding chemotherapy-induced peripheral neuropathy. F1000Res. 2020;9.

147. Bruna J, et al. Efficacy of a novel sigma-1 receptor antagonist for oxaliplatin-induced neuropathy: a randomized, double-blind placebo-controlled phase IIa clinical trial. Neurotherapeutics. 2018;15(1):178-89.

148. Peng WW, et al. Neurobiological mechanisms of TENS-induced analgesia. Neuroimage. 2019;195:396-408.

149. Loh J, Gulati A. The use of transcutaneous electrical nerve stimulation (TENS) in a major cancer center for the treatment of severe cancer-related pain and associated disability. Pain Med. 2015;16(6):1204-10.

150. Hurlow A, et al. Transcutaneous electric nerve stimulation (TENS) for cancer pain in adults. Cochrane Database Syst Rev. 2012;3:CD006276.

151. Smith TJ, et al. Pilot trial of a patient-specific cutaneous electrostimulation device (MC5-A Calmare(R)) for chemotherapy-induced peripheral neuropathy. J Pain Symptom Manag. 2010;40(6):883-91.

152. Mainkar $\mathrm{O}$, et al. Pilot study in temporary peripheral nerve stimulation in oncologic pain. Neuromodulation. 2020;23(6):819-26.

153. Sdrulla AD, Guan Y, Raja SN. Spinal cord stimulation: clinical efficacy and potential mechanisms. Pain Pract. 2018;18(8):1048-67.

154. Cata JP, et al. Spinal cord stimulation relieves chemotherapyinduced pain: a clinical case report. J Pain Symptom Manag. 2004;27(1):72-8.

155. Luckett $\mathrm{T}$, et al. Assessment and management of adult cancer pain: a systematic review and synthesis of recent qualitative studies aimed at developing insights for managing barriers and optimizing facilitators within a comprehensive framework of patient care. J Pain Symptom Manag. 2013;46(2):229-53.

156. Syrjala KL, et al. Psychological and behavioral approaches to cancer pain management. J Clin Oncol. 2014;32(16):1703-11.

157. Jacobsen PB, Andrykowski MA. Tertiary prevention in cancer care: understanding and addressing the psychological dimensions of cancer during the active treatment period. Am Psychol. 2015;70(2):134-45.

158. Moloney NA, et al. Psychological factors are associated with pain at all time frames after breast cancer surgery: a systematic review with meta-analyses. Pain Med. 2021;22(4):915-47.

159. Deng G. Integrative medicine therapies for pain management in cancer patients. Cancer J. 2019;25(5):343-8. 